\title{
Spectrum of Third Window Abnormalities: Semicircular Canal Dehiscence and Beyond
}

\author{
(D) M.-L. Ho, (D) Moonis, (D)C.F. Halpin, and (D).D. Curtin
}

\begin{abstract}
SUMMARY: Third window abnormalities are defects in the integrity of the bony structure of the inner ear, classically producing sound-/ pressure-induced vertigo (Tullio and Hennebert signs) and/or a low-frequency air-bone gap by audiometry. Specific anatomic defects include semicircular canal dehiscence, perilabyrinthine fistula, enlarged vestibular aqueduct, dehiscence of the scala vestibuli side of the cochlea, X-linked stapes gusher, and bone dyscrasias. We discuss these various entities and provide key examples from our institutional teaching file with a discussion of symptomatology, temporal bone CT, audiometry, and vestibular-evoked myogenic potentials.
\end{abstract}

ABBREVIATIONS: EVAS = enlarged vestibular aqueduct syndrome; SSCCD = superior semicircular canal dehiscence

T hird window abnormalities are defects in the integrity of the bony structure of the inner ear, first described by Minor et al in 1998. ${ }^{1}$ In 2008, Merchant and Rosowski ${ }^{2}$ proposed a universal theory for the underlying mechanism of hearing loss accompanying these defects. Normal sound conduction is transmitted through the oval and round windows, which serve as fluid interfaces between air in the middle ear and perilymphatic fluid spaces of the inner ear. Various conditions can enlarge existing bony channels or create additional defects in the bony labyrinth, producing hydrodynamic third windows. Potential third windows include bony dehiscence of the semicircular canals, enlargement of the opening of the vestibular aqueduct, dehiscence of the scala vestibuli side of the cochlea, and abnormal bony thinning between the cochlea and vascular channels. At audiometry, there is a characteristic low-frequency air-bone gap due to decreased air conduction and increased bone conduction. ${ }^{2}$

Figure $1 A$ illustrates the mechanism of air-conducted sound in normal ears, and Fig $1 B$ demonstrates how third window shunt-

From the Department of Radiology (M.-L.H.), Mayo Clinic, Rochester, Minnesota; Department of Radiology (G.M.), Columbia University, New York, New York; and Departments of Otolaryngology (C.F.H.) and Radiology (H.D.C.), Massachusetts Eye and Ear Infirmary, Boston, Massachusetts.

Paper previously presented at: Morrison Research Day, May 23, 2011, Beth Israel Deaconess Radiology, Boston, Massachusetts; Resident Research Day, June 10, 2011, Beth Israel Deaconess Medical Center, Boston, Massachusetts; Annual Meeting of the American Society of Neuroradiology and the Foundation of the ASNR Symposium, June 4-9, 2011; Seattle, Washington; and Annual Meeting of the Eastern Neuroradiological Society, September 15-18, 2011, Chatham, Massachusetts.

Please address correspondence to Mai-Lan Ho, MD, Department of Radiology, Mayo Clinic, 200 First St SW, Rochester, MN 55905; e-mail: ho.mai-lan@mayo.edu

- Indicates open access to non-subscribers at www.ajnr.org

http://dx.doi.org/10.3174/ajnr.A4922 ing effects decrease air conduction. The 2 physiologic windows between the middle and inner ear are the oval window, which transmits vibrations from the auditory ossicles, and the round window of the cochlea. With air conduction, there is physiologic entrainment of the oval and round windows due to coupling by incompressible perilymph. Pressure differences between the cochlear perilymphatic spaces activate hair cells and create the perception of sound. In the presence of a third window, incoming acoustic energy from the oval window is shunted away, decreasing transmission to the round window. This result reduces sound perception because less acoustic energy is available to the hair cells.

In contrast, Fig $1 C$ illustrates the mechanism of bone-conducted sound in normal ears, and Fig $1 D$ demonstrates how third window shunting effects paradoxically increase bone conduction. With bone conduction, vibrations throughout the otic capsule produce differential outward motion of the oval and round windows, due to unequal impedance of these 2 structures. The pressure difference across the basilar membrane creates the perception of sound. The presence of a third window involving the semicircular canals, vestibular aqueduct, or scala vestibuli side of the cochlea lowers the apparent impedance. This feature has the opposite effect of increasing sound perception in proportion to the differential acoustic energy across the basilar membrane. ${ }^{2}$

In this article, we discuss the spectrum of third window abnormalities, including superior semicircular canal dehiscence (SSCCD), posterior semicircular canal dehiscence, perilabyrinthine fistula, enlarged vestibular aqueduct, $\mathrm{X}$-linked stapes gusher, and bone dyscrasias. We review the literature for each disease entity and provide key examples from our institutional teaching file with 

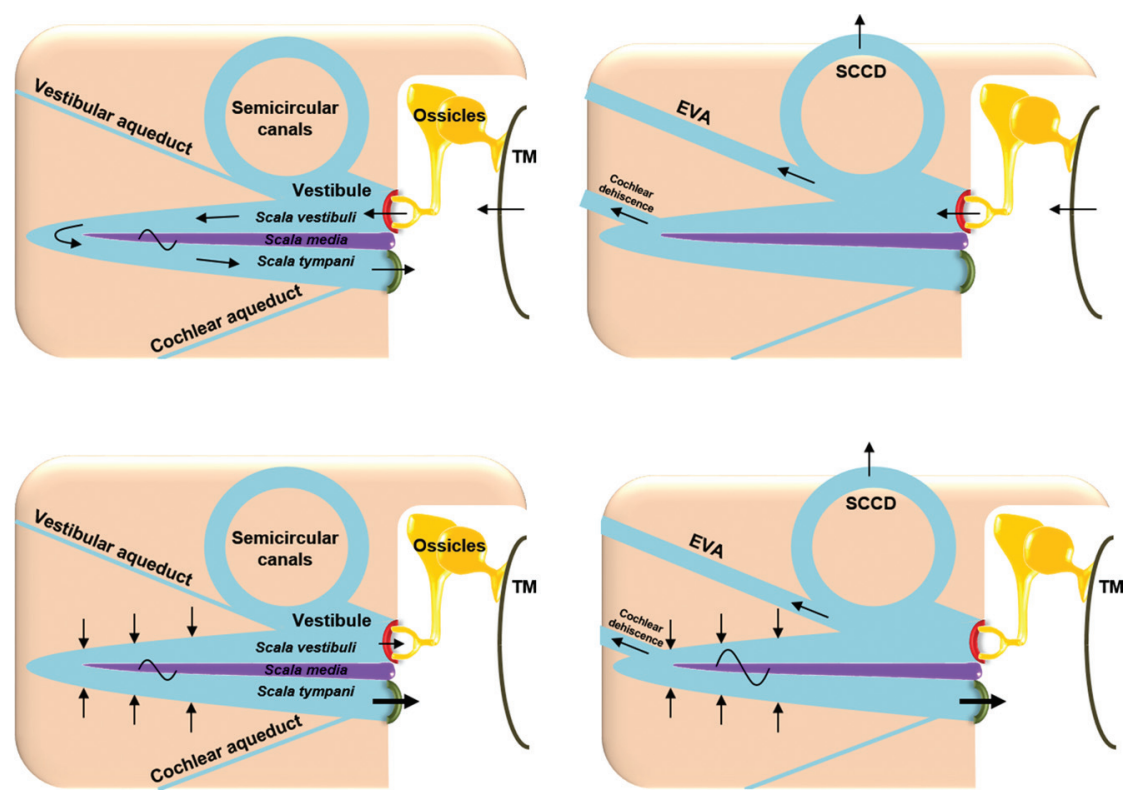

FIG 1. Mechanisms of air- and bone-conducted sound in healthy and third window anatomy. A, Normal air conduction. Vibrations of the tympanic membrane are transmitted inward through the auditory ossicles and oval window. Energy is then conducted through the incompressible perilymph, producing equal and outward motion of the round window. The difference in vibration between the oval and round windows generates a pressure gradient across the basilar membrane, activating hair cells and creating the perception of sound. B, Decreased air conduction in third window anatomy. Due to shunting across third windows (semicircular canal dehiscence [SCCD], EVAS, cochlear dehiscence), there is decreased energy transmission from the oval window to the round window. The decrease in pressure gradient across the basilar membrane yields reduced sound perception. C, Normal bone conduction. Vibrations are transmitted throughout the otic capsule. This transmission results in differential outward motion of the oval and round windows due to unequal impedance of these 2 structures. The resulting pressure difference across the basilar membrane enables sound perception. $D$, Increased bone conduction in third window anatomy. Due to shunting across third windows, there is decreased motion of the oval window on the scala vestibuli side of the cochlea. However, the motion of the round window on the scala tympani side is unchanged. This phenomenon artifactually elevates the pressure difference across the basilar membrane, resulting in increased sound perception. TM indicates tympanic membrane; yellow, auditory ossicles; beige, otic capsule; red, oval window; green, round window; blue, perilymph; purple, basilar membrane. Adapted with permission from Merchant SN, Rosowski J. Conductive hearing loss caused by third window lesions of the inner ear. Otol Neurotol 2008;29:282-89.
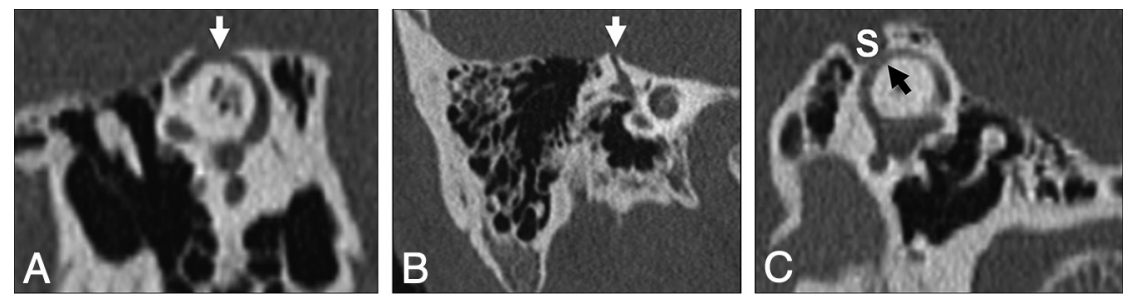

FIG 2. Temporal bone CT in the Pöschl $(A)$ and Stenvers $(B)$ planes demonstrating a large defect (arrows) in the roof of the right superior semicircular canal. C, Temporal bone CT Pöschl reconstruction demonstrates dehiscence of the left superior semicircular canal (arrow) into the superior petrosal sinus (S).
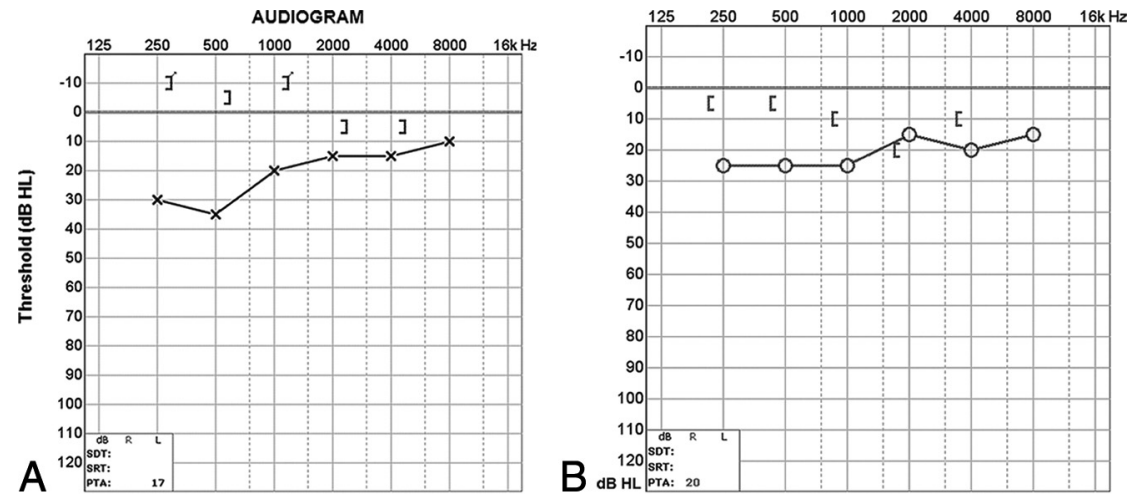

FIG 3. A, Audiogram of the right superior semicircular canal dehiscence with increased bone conduction (brackets) and decreased air conduction (crosses). The air-bone gap exceeds $10 \mathrm{~dB}$ at low sound frequencies $(<1 \mathrm{kHz})$, the range at which acoustic energy is readily dissipated (described in the text). $B$, Audiogram of left superior semicircular canal dehiscence into the superior petrosal sinus. There is increased bone conduction (brackets) and decreased air conduction (circles), similar to typical SSCCD. 
VEMP Threshold (dB pSP)

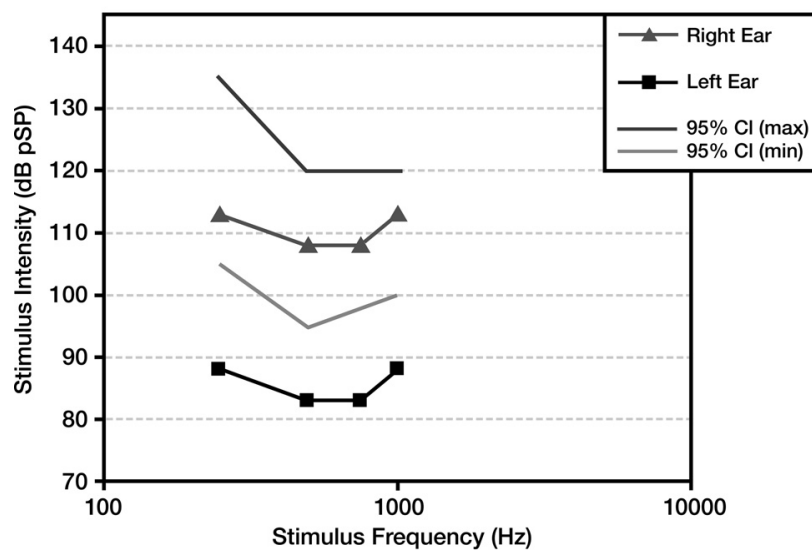

FIG 4. Vestibular-evoked myogenic potentials in superior semicircular canal dehiscence. Compared with the normal right ear (triangle) range (lines), the left ear demonstrates an abnormally sensitive response threshold (squares) across all tested stimulus frequencies. The lower thresholds indicate increased excitation of otolithic organs due to third window acoustic transmission.

discussion of symptomatology, temporal bone CT, audiometry, and vestibular-evoked myogenic potentials.

\section{Superior Semicircular Canal Dehiscence}

Superior semicircular canal dehiscence refers to focal loss of the bony wall of the superior semicircular canal. The prevalence is reported as $2.1 \%-10.7 \%$ on temporal bone CT and $0.5 \%-0.6 \%$ at postmortem studies. SSCCD is idiopathic, though the proposed risk factors include congenital underdevelopment of bone overlying the semicircular canal, shear stress from trauma, increased pressure due to Valsalva maneuvers, and gradual erosion by vascular pulsations. ${ }^{3-10}$ A special subset of SSCCD involves dehiscence of the superior semicircular canal into the superior petrosal sinus, which normally grooves the superior margin of the petrous portion of the temporal bone. Neurovascular foramina can serve as potential windows between the middle and inner ear but are normally not associated with abnormalities of sound transmission due to their small cross-sectional area. Vascular abnormalities that enlarge the foramina and/or communicate with the bony labyrinth can produce clinically significant acoustic dissipation. It is theorized that acoustic decompression through the dura mater acts as a third window equivalent, permitting shunting of acoustic energy into the subarachnoid space or into the vessel itself., ${ }^{2,11,12}$

Patients with SSCCD typically present with vertigo and nystagmus induced by loud noises (Tullio phenomenon) or increases in external auditory canal pressure (Hennebert sign). ${ }^{5}$ High-resolution temporal bone CT images (maximum thickness, 0.5$0.625 \mathrm{~mm}$ ) should be evaluated to avoid volume averaging, which can obscure a focal osseous defect. Multiplanar reconstructions and reformats parallel to (Pöschl plane) and perpendicular to (Stenvers plane) the superior semicircular canal are used to demonstrate the dehiscence to best advantage (Fig 2)., ${ }^{3,8,9}$

At audiometry, a characteristic air-bone gap results from increased bone and decreased air conduction. This phenomenon occurs most significantly at lower sound frequencies (below 1 $\mathrm{kHz}$ ), a range at which acoustic energy is readily dissipated (Fig 3). At higher frequencies, there is a small or no gap because propor-

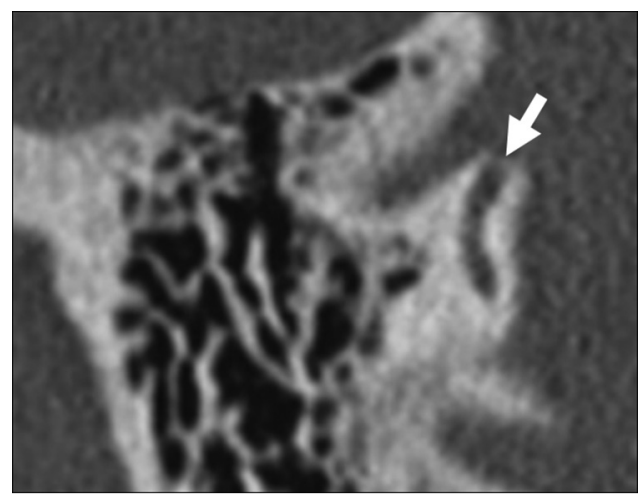

FIG 5. Posterior semicircular canal dehiscence. Temporal bone CT in the coronal plane demonstrates a defect (arrow) in the roof of the posterior semicircular canal.

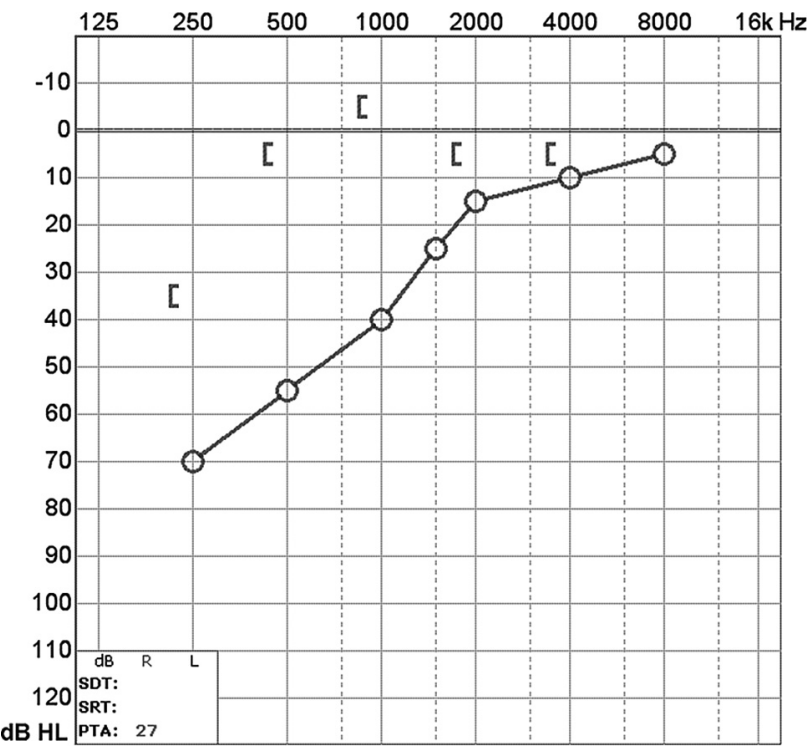

FIG 6. Audiogram of posterior semicircular canal dehiscence with increased bone conduction (brackets) and decreased air conduction (circles). Findings are compatible with posterior semicircular canal dehiscence (described in the text).

tionally less acoustic energy is shunted by the third window. Vestibular-evoked myogenic potential testing may show abnormally low response thresholds on the side of pathology. The effective impedance is reduced; this reduction results in increased transmission of acoustic energy at the saccule (Fig 4). Because middle ear pathology can also produce an air-bone gap, tympanometry and acoustic reflexes may be tested to verify that the air-bone gap does not result from an inefficient middle ear. ${ }^{3,10}$

At Massachusetts Eye and Ear Infirmary, 116 patients (161 ears) with SSCCD were included in the teaching file from 2000 to 2011. Of these, 5/161 ears demonstrated dehiscence into the superior petrosal sinus. Reported symptoms included hearing loss in $60 / 116$ patients $(52 \%)$, vertigo in $54 / 116(46 \%)$, pulsatile tinnitus in 35/116 (30\%), autophony in 31/116 (27\%), and oscillopsia in $16 / 116(14 \%)$. Audiometry was evaluable in 92 ears, with $71 / 92$ ears (77\%) supporting the diagnosis of semicircular canal dehiscence and 21/92 (23\%) being normal. Vestibular-evoked myogenic potential testing was evaluable in 39 ears, with 22/39 

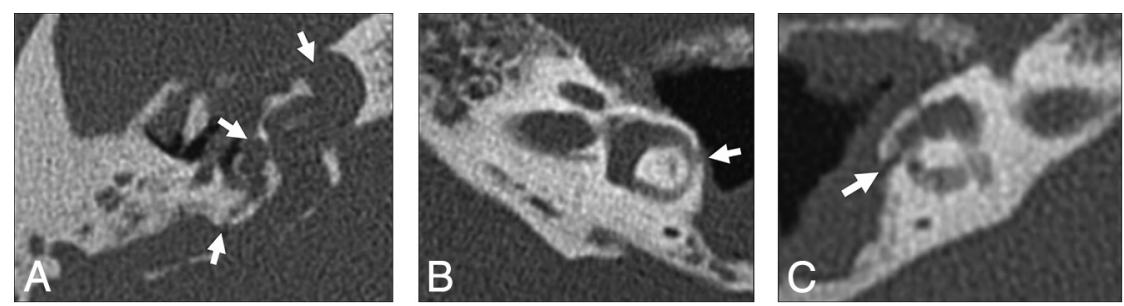

FIG 7. Inflammatory causes of perilabyrinthine fistula. A, Cholesteatoma. Axial CT shows an expansile, widely destructive soft-tissue mass centered in the middle ear with erosion into the cochlea, vestibule, and posterior semicircular canal (arrows). B, Recurrent otitis media. Axial CT identifies residual soft-tissue opacity in the middle ear, with a fistula (arrow) extending through the otic capsule into the lateral semicircular canal. C, Invasive fungal infection. Axial CT illustrates heterogeneous soft tissue centered in the middle ear, with invasion through the otic capsule into the lateral semicircular canal (arrow).

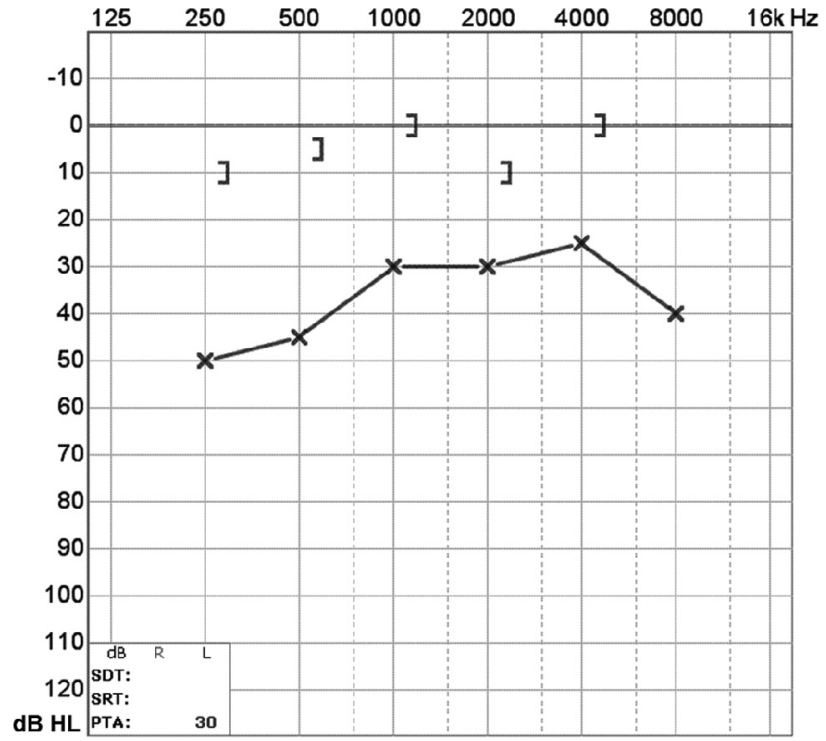

FIG 8. Audiogram of a cholesteatoma shows an air-bone gap of middle ear origin. There is decreased air conduction (crosses) relative to normal bone conduction (brackets). The resulting air-bone gap is present at both high and low sound frequencies. Given the background abnormality, it is not possible to detect the presence of superimposed third-window effects.

ears (56\%) supporting the diagnosis of SSCCD and 17/39 (44\%) being normal.

\section{Posterior Semicircular Canal Dehiscence}

Posterior semicircular canal dehiscence is uncommon, with a reported frequency of $0.3 \%-4.5 \%$ on temporal bone CT and a postmortem prevalence of $0.2 \%$. The condition can occur sporadically or in association with superior canal dehiscence. Clinically, patients may also demonstrate the Tullio and Hennebert signs. Thin-collimation CT demonstrates the focal bony defect in the posterior semicircular canal (Fig. 5). Audiometry reveals an airbone gap at frequencies below $1 \mathrm{kHz}$ (Fig 6).,13-15

At Massachusetts Eye and Ear Infirmary, 5 patients ( 8 ears) with posterior semicircular canal dehiscence were included in the teaching file from 2000 to 2011. Reported symptoms included hearing loss in $3 / 5(60 \%)$, pulsatile tinnitus in $4 / 5$ (80\%), autophony in $2 / 5(40 \%)$, classic vertigo in $1 / 5(20 \%)$, and nonclassic vertigo in $1 / 5(20 \%)$. Audiometry was evaluable in 4 ears, with $3 / 4$ ears $(75 \%)$ supporting the diagnosis of third window abnormalities and 1/4 (25\%) being normal.
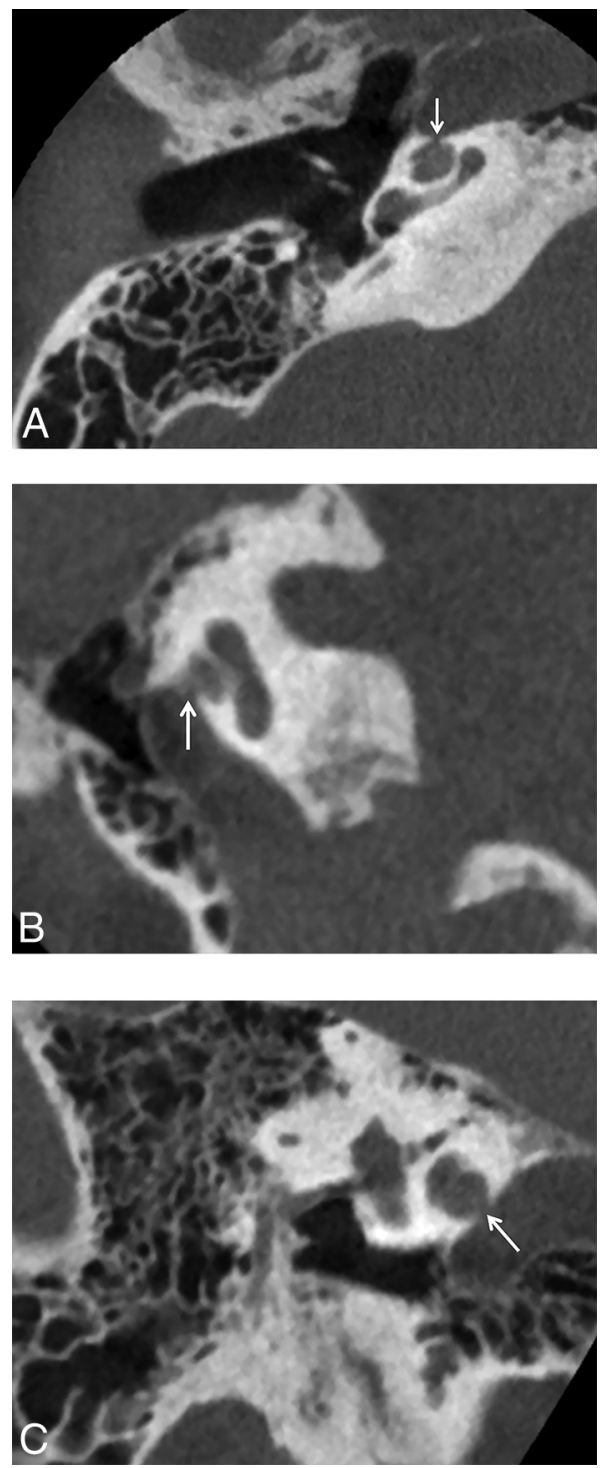

FIG 9. Carotid-cochlear dehiscence. Axial CT (A), Pöschl reformat (B), and Stenvers $(A)$ reformat demonstrate communication between the apical turn of the cochlea and the carotid canal (arrows).

\section{Perilabyrinthine Fistula}

Destructive middle ear processes that erode the attenuated otic capsule can produce inadvertent communication with the inner ear, known as a perilabyrinthine fistula. When this involves the semicircular canals, vestibule, and/or scala vestibuli side of the cochlea, third window mechanics can result. The most common 


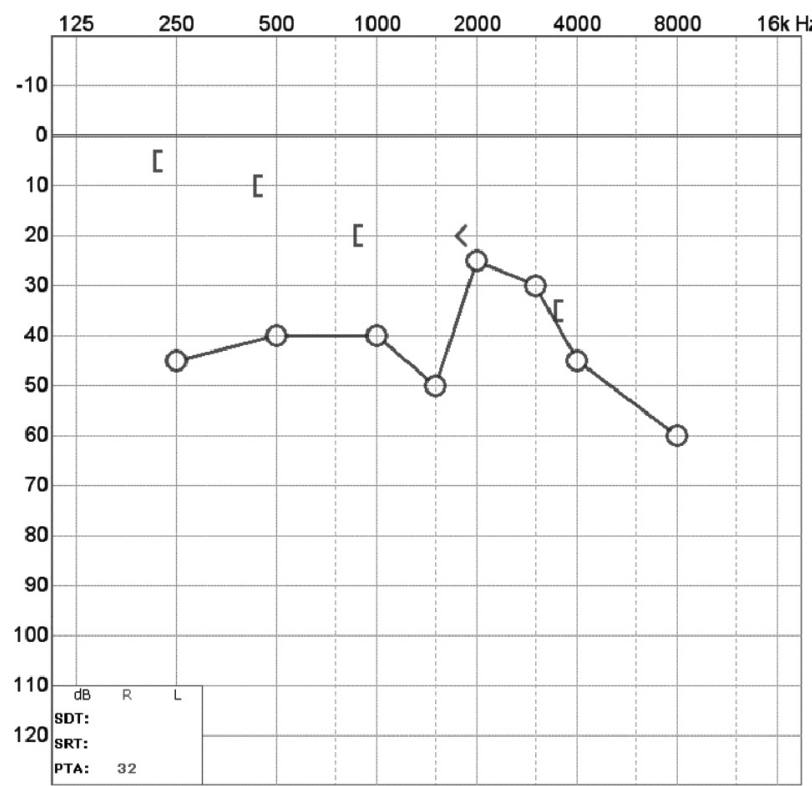

FIG 10. Audiogram of carotid-cochlear dehiscence. There is increased bone conduction (brackets) and decreased air conduction (circles), with a progressively larger air-bone gap at lower frequencies. In this case, the ipsilateral acoustic reflex was present, indicating that the ossicular chain was free to move with the action of the stapedius muscle. Therefore no middle ear pathology such as serous otitis, otosclerosis, or cholesteatoma was responsible for the air-bone gap.

etiology is chronic infection/inflammation, such as cholesteatoma or otitis media. The lateral semicircular canal is most frequently involved due to its location directly adjacent to the middle ear (Fig 7). On audiometry, cholesteatoma demonstrates a characteristic air-bone gap of middle ear origin, which is present at both low and high sound frequencies due to superimposed ossicular chain pathology (Fig 8). 3,16,17 Rarely, cochlear-carotid dehiscence with the absence of the intervening bony partition can also occur (Fig 9). On audiometry, this condition demonstrates an air-bone gap that is greater at lower frequencies, similar to other third windows (Fig 10). ${ }^{18-20}$

Other potential causes of perilabyrinthine fistula include trauma (Fig 11), an operation, and benign and neoplastic masses (Fig 12). Transverse temporal bone fractures are more likely to involve the petrous pyramid and violate the otic capsule. With this background abnormality, it is difficult or impossible to identify superimposed third window effects. In such cases, hearing is generally unrecoverable and audiometry is not performed, so a typical third window effect cannot be demonstrated. ${ }^{21,22}$

At Massachusetts Eye and Ear Infirmary, 43 patients (60 ears) with perilabyrinthine fistula of the semicircular canals, vestibule, and/or scala vestibuli side of the cochlea were included in the teaching file from 2000 to 2011. Etiologies were inflammatory in $45 / 60(75 \%)$, traumatic/iatrogenic in 9/60 (15\%), and neoplastic in $6 / 60(10 \%)$. Anatomic sites of involvement included the lateral semicircular canal in $31 / 60$ (52\%), the superior semicircular canal in $12 / 60(20 \%)$, the posterior semicircular canal in $4 / 60(7 \%)$, the cochlea in 13/60 (22\%), and the vestibule in 11/60 (18\%). Reported symptoms included hearing loss in $21 / 43$ (49\%), vertigo in $13 / 43(31 \%)$, otorrhea in $13 / 43(30 \%)$, and otalgia in $10 / 43$ (23\%).
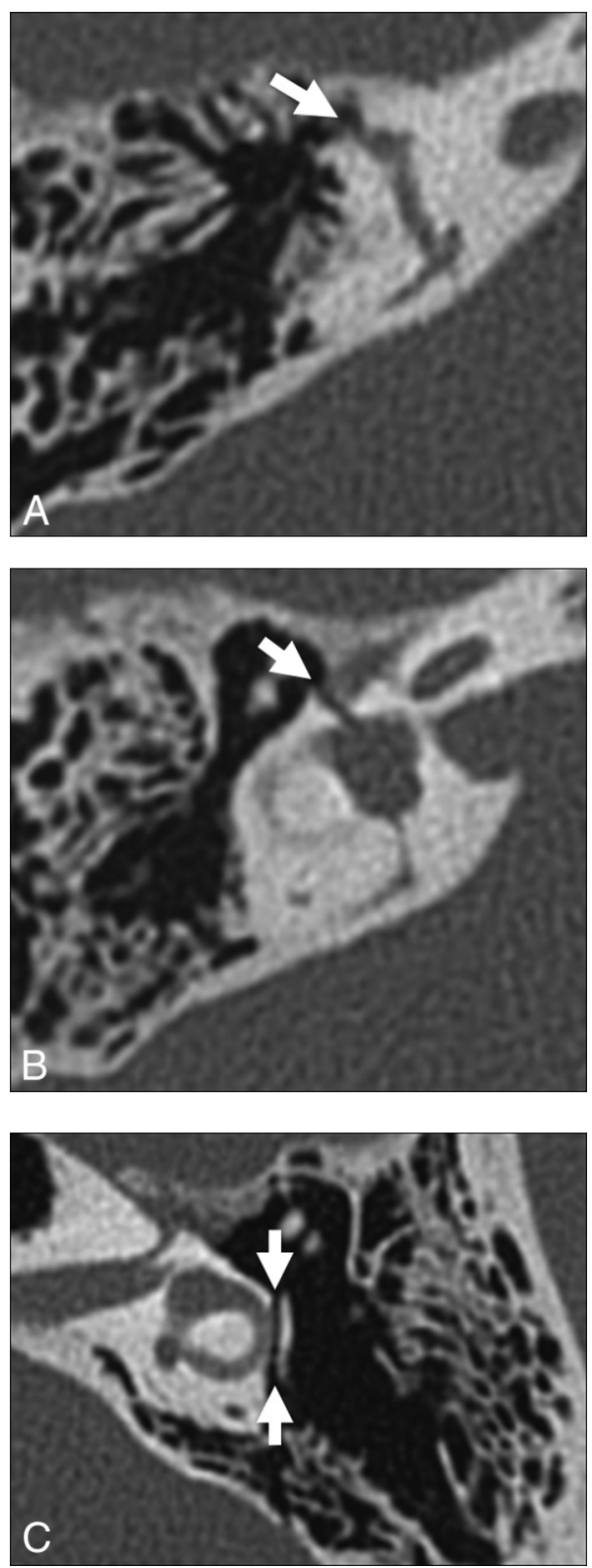

FIG 11. Traumatic causes of perilabyrinthine fistula. A, Transverse temporal bone fracture through the superior semicircular canal (arrow). $B$, Transverse temporal bone fracture across the bony vestibule (arrow). C, Transverse temporal bone fracture through the otic capsule (arrows) with unroofing of the lateral semicircular canal.

\section{Enlarged Vestibular Aqueduct}

Enlarged vestibular aqueduct syndrome (EVAS) is a pathologic enlargement of the vestibular aqueduct at the level of the endolymphatic duct. In EVAS, the connection of the vestibular aqueduct to the vestibule is larger than normal, and this connection acts as a third window transmitting acoustic energy through the aqueduct to the dura. CT criteria are classically based on the transverse dimension of the vestibular aqueduct (Valvassori criterion: midpoint of $\geq 1.5 \mathrm{~mm}$; Cincinnati criteria: midpoint of $\geq 1 \mathrm{~mm}$ or operculum of $\geq 2 \mathrm{~mm}$ ), though the adjacent posterior semicircular canal often serves as a standard reference. ${ }^{23-27}$ Normative values by using the $45^{\circ}$ oblique (Pöschl) projection have recently been established as $0.3-0.9 \mathrm{~mm}$ (mean, $0.5 \mathrm{~mm}$ ) at the midpoint. ${ }^{28}$ The finding is frequently bilateral and can be seen either in 

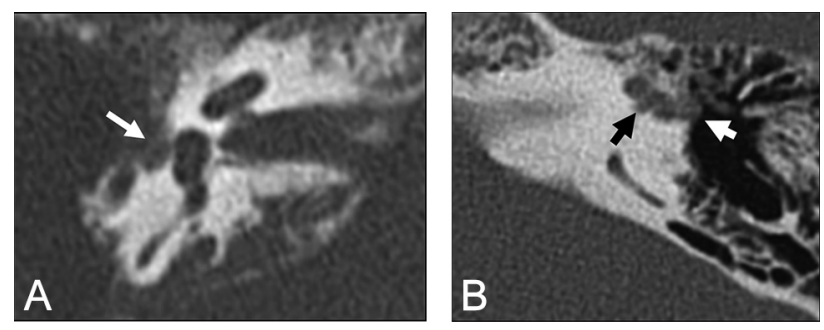

FIG 12. Neoplastic causes of perilabyrinthine fistula. A, Squamous cell carcinoma. Axial CT scan shows destructive soft tissue filling the middle ear and eroding through the otic capsule (arrow). B, Facial nerve venous malformation. Axial CT scan shows a lobulated soft-tissue density extending from the geniculate ganglion (white arrow) through the otic capsule and into the superior semicircular canal (black arrow).
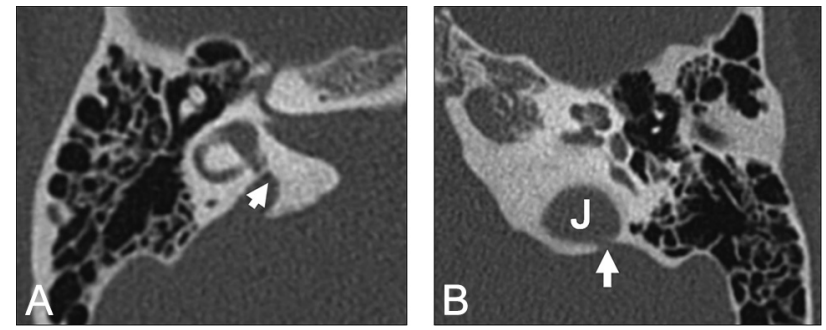

FIG 13. A, Enlarged vestibular aqueduct syndrome. Axial CT scan shows a dilated vestibular aqueduct (arrow) at its junction with the vestibule. $B$, Axial CT scan shows dehiscence of the vestibular aqueduct (arrow) into the jugular foramen (J).

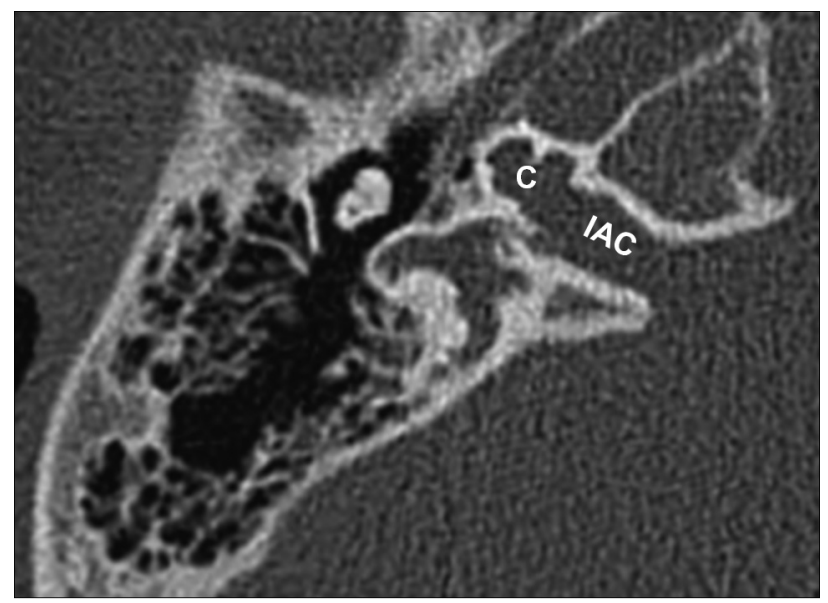

FIG 14. X-linked stapes gusher. Axial CT scan shows a dysplastic cochlea (C) with a modiolar deficiency and absence of the lamina cribrosa, resulting in a direct communication with an enlarged internal auditory canal (IAC).

isolation or with various congenital conditions, including Pendred syndrome; coloboma, heart defect, atresia choanae (also known as choanal atresia), retarded growth and development, genital abnormality, and ear abnormality (CHARGE syndrome); and branchiooto-renal syndrome. It has been reported that dehiscence of the vestibular aqueduct into the jugular bulb also exhibits third window mechanics (Fig 13). ${ }^{29-33}$

At audiometry, patients present with a complex and variable pattern of hearing loss. The sensorineural component of hearing loss is thought to result from potential associated cochleovestibular malformations and manifests at higher sound frequencies.
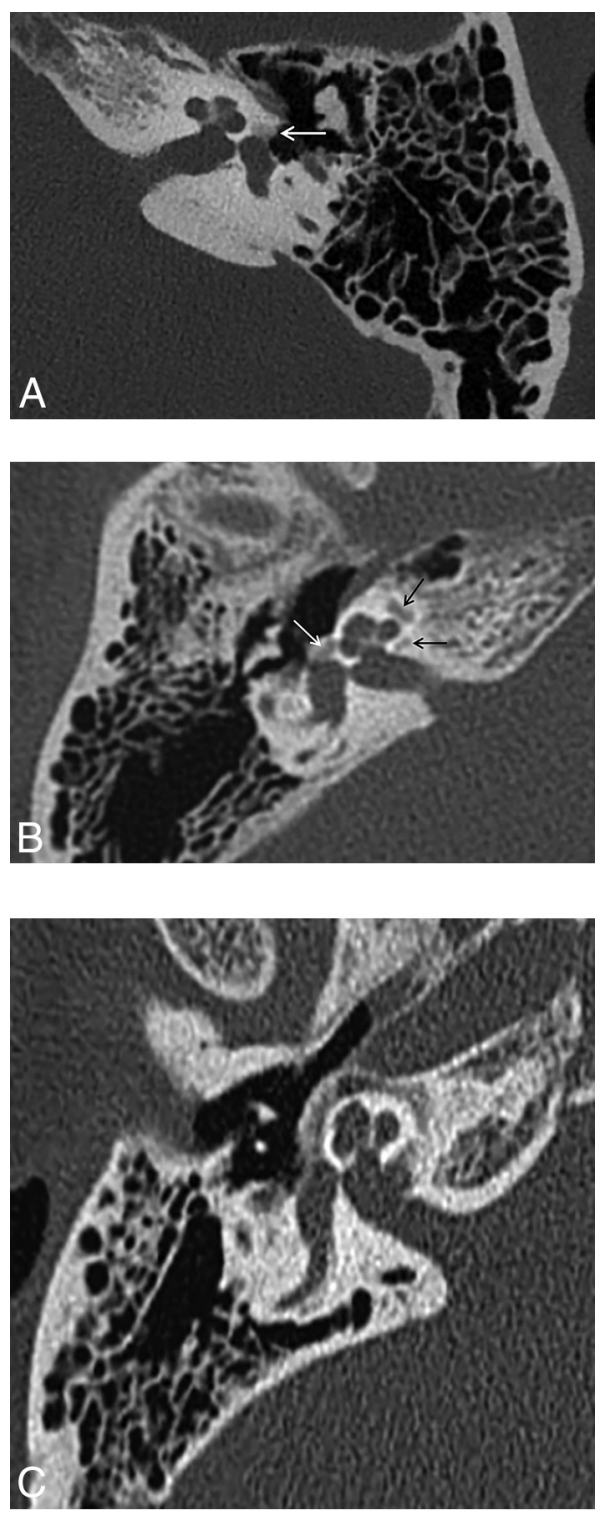

FIG 15. Otospongiosis. A, Fenestral otospongiosis. Axial CT scan shows lucency at the fissula ante fenestram (arrow). B, Fenestral and retrofenestral otospongiosis. Axial CT scan shows lucency at the fissula ante fenestram (white arrow) and surrounding the cochlea (black arrows). C, Advanced otospongiosis. Axial CT scan late in the course of disease demonstrates a complete ring of pericochlear lucency.

The conductive component of hearing loss results from acoustic energy dissipation through an enlarged third window where the vestibular aqueduct joins the vestibule. This is evidenced by an audiometric air-bone gap at low frequencies but may be missed if bone conduction is not measured, particularly in young children who cannot tolerate a full audiologic examination., ${ }^{2,34-37}$ Vestibular-evoked myogenic potential studies may demonstrate increased vestibular organ responses on the side of pathology. ${ }^{38,39}$

At Massachusetts Eye and Ear Infirmary, 98 patients (165 ears) with EVAS were included in the teaching file from 2000 to 2011. Sixty of 165 ears (36\%) demonstrated associated cochleovestibular malformations. Reported symptoms at the time of imaging included hearing loss in 67/98 patients (68\%) and vertigo in 6/98 $(6 \%)$. Audiogram findings for EVAS varied widely, demonstrating mixed sensorineural and conductive components. Six patients 


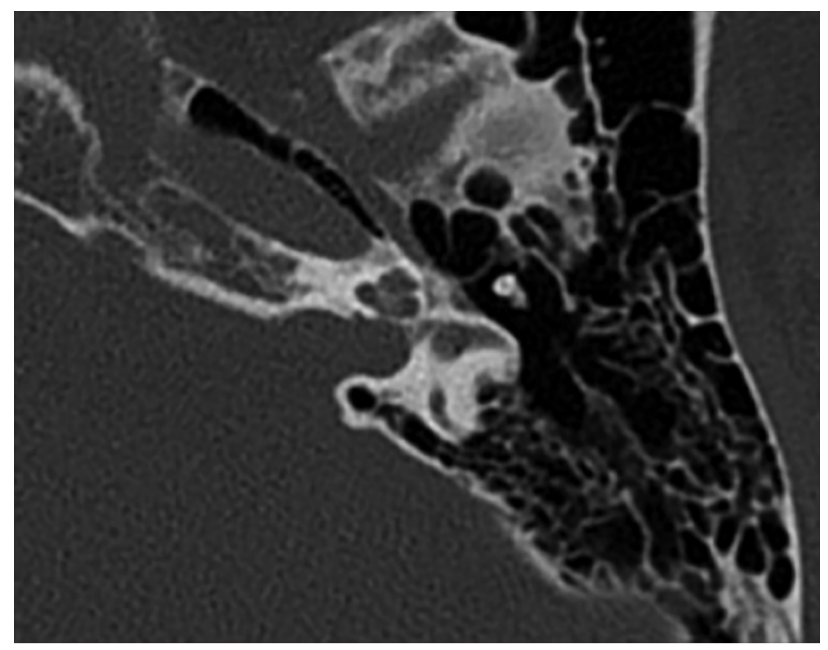

FIG 16. Osteogenesis imperfecta. Axial CT scan shows otic capsule demineralization with multiple vague lucencies, including the fissula ante fenestram, pericochlear region, and area adjacent to the internal auditory canal. Radiologically, this is indistinguishable from otospongiosis.

(7 ears) demonstrated vestibular aqueduct dehiscence into the jugular bulb. Audiometry was evaluable in 7 ears, with 1/7 (14\%) showing the classic air-bone gap of the third window disorder.

\section{X-Linked Stapes Gusher}

$\mathrm{X}$-linked stapes gusher is a congenital disorder resulting from a loss-of-function mutation in the POU3F4 gene at the DFN3 locus of the X chromosome. Patients are almost exclusively male and present with mixed hearing loss at birth, rapidly progressing to severe deafness in the first decade. ${ }^{40,41}$ Female carriers of the gene may be healthy or may have less severe hearing loss. ${ }^{42,43}$ The spectrum of abnormalities on CT includes cochlear hypoplasia with modiolar deficiency, absence of the lamina cribrosa, an enlarged internal auditory canal, and an enlarged labyrinthine facial nerve canal (Fig 14). ${ }^{44-47}$

On audiometry, patients with X-linked stapes gusher typically demonstrate a mixed hearing loss. The sensorineural component of hearing loss results from the cochleovestibular malformation. The conductive component results from absence of the lamina cribrosa, which normally separates the basal turn of the cochlea from the internal auditory canal. Therefore, there is direct communication of CSF between the subarachnoid and perilymphatic spaces, acting as a third window. ${ }^{2,48}$

At Massachusetts Eye and Ear Infirmary, 9 patients (18 ears) with X-linked stapes gusher were included in the teaching file from 2000 to 2011. On CT, all patients demonstrated bilateral temporal bone abnormalities. One hundred percent of patients had hearing loss, with mixed sensorineural and conductive components on audiometry.

\section{Bone Dyscrasias}

Bone dyscrasias such as Paget disease, osteogenesis imperfecta, and otospongiosis are rarely reported in conjunction with third window mechanics. In the adult, the bony labyrinth is composed of mature avascular enchondral bone, which undergoes virtually no remodeling after development. Metabolic bone diseases decrease the acoustic impedance both into and out of the bone, presumably acting as an anatomically diffuse or "distributed" third window (Figs 15 and 16). Postmortem micro-CT and temporal bone histology have demonstrated communications between the middle and inner ear that are too small to visualize on conventional CT. Air-bone gaps on audiometry have been reported in the literature but may be obscured by large conductive losses. ${ }^{2,49-54}$

\section{CONCLUSIONS}

Third window lesions classically present with auditory (hearing loss) and vestibular (Tullio and Hennebert syndromes) symptoms. On temporal bone CT, specific anatomic defects include superior semicircular canal dehiscence, posterior semicircular canal dehiscence, perilabyrinthine fistula, enlarged vestibular aqueduct, X-linked stapes gusher, and bone dyscrasias. Awareness of the various etiologies and correlation with an audiologic examination will help in diagnosing this multifaceted disorder.

\section{ACKNOWLEDGMENT}

We thank Garyfallia Pagonis for her expert assistance with graphics.

Disclosures: Gul Moonis_UNRELATED: Other: a blind reader for RadMD. Chris F. Halpin-UNRELATED: Payment for Lectures (including service on Speakers Bureaus): Auris Medical, Comments: travel to a conference in Dallas in 2015 on sudden sensory loss. Hugh D. Curtin—UNRELATED: Payment for Lectures (including service on Speakers Bureaus): International Institute for Continuing Medical Education, Comments: lectures in Continuing Medical Education courses; Royalties: Elsevier (book royalties)

\section{REFERENCES}

1. Minor LB, Solomon D, Zinreich JS, et al. Sound- and/or pressureinduced vertigo due to bone dehiscence of the superior semicircular canal. Arch Otolaryngol Head Neck Surg 1998;124:249-58 CrossRef Medline

2. Merchant SN, Rosowski JJ. Conductive hearing loss caused by thirdwindow lesions of the inner ear. Otol Neurotol 2008;29:282-89 CrossRef Medline

3. Chien WW, Carey JP, Minor LB. Canal dehiscence. Curr Opin Neurology 2011;24:25-31 CrossRef Medline

4. Stimmer H, Hamann KF, Zeiter S, et al. Semicircular canal dehiscence in HR multislice computed tomography: distribution, frequency, and clinical relevance. Eur Arch Otorhinolaryngol 2012;269: 475-80 CrossRef Medline

5. Crovetto M, Whyte J, Rodriguez OM, et al. Anatomo-radiological study of the superior semicircular canal dehiscence: radiological considerations of superior and posterior semicircular canals. Eur J Radiol 2010;76:167-72 CrossRef Medline

6. Chen EY, Paladin A, Phillips G, et al. Semicircular canal dehiscence in the pediatric population. Int J Pediatr Otorhinolaryngol 2009;73: 321-27 CrossRef Medline

7. Loke SC, Goh JP. Incidence of semicircular canal dehiscence in Singapore. Br J Radiol 2009;82:371-73 CrossRef Medline

8. Cloutier JF, Bélair M, Saliba I. Superior semicircular canal dehiscence: positive predictive value of high-resolution CT scanning. Eur Arch Otorhinolaryngol 2008;265:1455-60 CrossRef Medline

9. Sequeira SM, Whiting BR, Shimony JS, et al. Accuracy of computed tomography detection of superior canal dehiscence. Otol Neurotol 2011;32:1500-05 CrossRef Medline

10. Yuen HW, Boeddinghaus R, Eikelboom RH, et al. The relationship between the air-bone gap and the size of superior semicircular canal dehiscence. Otolaryngol Head Neck Surg 2009;141:689-94 CrossRef Medline

11. McCall AA, McKenna MJ, Merchant SN, et al. Superior canal dehiscence syndrome associated with the superior petrosal sinus in pediatric and adult patients. Otol Neurotol 2011;32:1312-19 CrossRef Medline

12. Koo JW, Hong SK, Kim DK, et al. Superior semicircular canal dehis- 
cence syndrome by the superior petrosal sinus. J Neurol Neurosurg Psychiatry 2010;81:465-67 CrossRef Medline

13. Krombach GA, DiMartino E, Schmitz-Rode T, et al. Posterior semicircular canal dehiscence: a morphologic cause of vertigo similar to superior semicircular canal dehiscence. Eur Radiol 2003;13:1444-50 Medline

14. Nomiya S, Cureoglu S, Kariya S, et al. Posterior semicircular canal dehiscence: a histopathologic human temporal bone study. Otol Neurotol 2010;31:1122-27 CrossRef Medline

15. Gopen Q, Zhou G, Poe D, et al. Posterior semicircular canal dehiscence: first reported case series. Otol Neurotol 2010;31:339-44 CrossRef Medline

16. Shinnabe A, Hara M, Hasegawa M, et al. Clinical characteristics and surgical benefits and problems of chronic otitis media and middle ear cholesteatoma in elderly patients older than 70 years. Otol Neurotol 2012;33:1213-17 CrossRef Medline

17. Ikeda R, Kobayashi T, Kawase T, et al. Risk factors for deterioration of bone conduction hearing in cases of labyrinthine fistula caused by middle ear cholesteatoma. Ann Otol Rhinol Laryngol 2012;121: 162-67 CrossRef Medline

18. Lund AD, Palacios SD. Carotid artery-cochlear dehiscence: a review. Laryngoscope 2011;121:2658-60 CrossRef Medline

19. Young RJ, Shatzkes DR, Babb JS, et al. The cochlear-carotid interval: anatomic variation and potential clinical implications. AJNR Am J Neuroradiol 2006;27:1486-90 Medline

20. Penido Nde O, Borin A, Fukuda Y, et al. Microscopic anatomy of the carotid canal and its relations with cochlea and middle ear. Braz J Otorhinolaryngol 2005;71:410-14 CrossRef Medline

21. Kang HM, Kim MG, Boo SH, et al. Comparison of the clinical relevance of traditional and new classification systems of temporal bone fractures. Eur Arch Otorhinolaryngol 2012;269: 1893-99 CrossRef Medline

22. Dahiya R, Keller JD, Litofsky NS, et al. Temporal bone fractures: otic capsule sparing versus otic capsule violating clinical and radiographic considerations. J Trauma 1999;47:1079-83 CrossRef Medline

23. Berrettini S, Forli F, Bogazzi F, et al. Large vestibular aqueduct syndrome: audiological, radiological, clinical, and genetic features. Am J Otolaryngol 2005;26:363-71 CrossRef Medline

24. Valvassori G, Clemis J. The large vestibular aqueduct syndrome. Laryngoscope 1978;88:273-78 Medline

25. Boston M, Halsted M, Meinzen-Derr J, et al. The large vestibular aqueduct: a new definition based on audiologic and computed tomography correlation. Otolaryngol Head Neck Surg 2007;136:972-77 CrossRef Medline

26. Sennaroglu L, Saatci I. A new classification for cochleovestibular malformations. Laryngoscope 2002;112:2230-41 CrossRef Medline

27. Saliba I, Gingras-Charland ME, St-Cyr K, et al. Coronal CT scan measurements and hearing evolution in enlarged vestibular aqueduct syndrome. Int J Pediatr Otorhinolaryngol 2012;76:492-99 CrossRef Medline

28. Lookabaugh S, Kelly HR, Carter MS, et al. Radiologic classification of superior canal dehiscence: implications for surgical repair. Otol Neurotol 2015;36:118-25 CrossRef Medline

29. Hourani R, Carey J, Yousem DM. Dehiscence of the jugular bulb and vestibular aqueduct: findings on 200 consecutive temporal bone computed tomography scans. J Comput Assist Tomogr 2005;29: 657-62 CrossRef Medline

30. Friedmann DR, Eubig J, Winata LS, et al. Prevalence of jugular bulb abnormalities and resultant inner ear dehiscence: a histopathologic and radiologic study. Otolaryngol Head Neck Surg 2012;147:750-56 CrossRef Medline

31. Friedmann DR, Eubig J, Winata LS, et al. A clinical and histopathologic study of jugular bulb abnormalities. Arch Otolaryngol Head Neck Surg 2012;138:66-71 CrossRef Medline

32. Kupfer RA, Hoesli RC, Green GE, et al. The relationship between jugular bulb-vestibular aqueduct dehiscence and hearing loss in pediatric patients. Otolaryngol Head Neck Surg 2012;146:473-77 CrossRef Medline
33. Friedmann DR, Le BT, Pramanik BK, et al. Clinical spectrum of patients with erosion of the inner ear by jugular bulb abnormalities. Laryngoscope 2010;120:365-72 CrossRef Medline

34. Mimura T, Sato E, Sugiura M, et al. Hearing loss in patients with enlarged vestibular aqueduct: air-bone gap and audiological Bing test. Int J Audiol 2005;44:466-69 CrossRef Medline

35. Arjmand EM, Webber A. Audiometric findings in children with a large vestibular aqueduct. Arch Otolaryngol Head Neck Surg 2004; 130:1169-74 CrossRef Medline

36. Merchant SN, Nakajima HH, Halpin C, et al. Clinical investigation and mechanism of air-bone gaps in large vestibular aqueduct syndrome. Ann Otol Rhinol Laryngol 2007;116:532-41 CrossRef Medline

37. Zhou G, Gopen Q, Kenna MA. Delineating the hearing loss in children with enlarged vestibular aqueduct. Laryngoscope 2008;118: 2062-66 CrossRef Medline

38. Zhou G, Gopen Q. Characteristics of vestibular evoked myogenic potentials in children with enlarged vestibular aqueduct. Laryngoscope 2011;121:220-25 CrossRef Medline

39. Sheykholeslami K, Schmerber S, Habiby Kermany M, et al. Vestibular-evoked myogenic potentials in three patients with large vestibular aqueduct. Hear Res 2004;190:161-68 CrossRef Medline

40. Schild C, Prera E, Lüblinghoff N, et al. Novel mutation in the homeobox domain of transcription factor POU3F4 associated with profound sensorineural hearing loss. Otol Neurotol 2011;32:690-94 CrossRef Medline

41. Friedman RA, Bykhovskaya $\mathrm{Y}, \mathrm{Tu}$ G, et al. Molecular analysis of the POU3F4 gene in patients with clinical and radiographic evidence of $\mathrm{X}$-linked mixed deafness with perilymphatic gusher. Ann Otol Rhinol Laryngol 1997;106:320-25 CrossRef Medline

42. Huang BY, Zdanski C, Castillo M. Pediatric sensorineural hearing loss, part 2: syndromic and acquired causes. AJNR Am J Neuroradiol 2012;33:399-406 CrossRef Medline

43. Marlin S, Moizard MP, David A, et al. Phenotype and genotype in females with POU3F4 mutations. Clin Genet 2009;76:558-63 CrossRef Medline

44. Papadaki E, Prassopoulos P, Bizakis J, et al. X-linked deafness with stapes gusher in females. Eur J Radiol 1998;29:71-75 CrossRef Medline

45. Talbot JM, Wilson DF. Computed tomographic diagnosis of $\mathrm{X}$-linked congenital mixed deafness, fixation of the stapedial footplate, and perilymphatic gusher. Am J Otol 1994;15:177-82 Medline

46. Kumar G, Castillo M, Buchman CA. X-linked stapes gusher: CT findings in one patient. AJNR Am J Neuroradiol 2003;24:1130-32 Medline

47. Cremers CW, Snik AF, Huygen PL, et al. X-linked mixed deafness syndrome with congenital fixation of the stapedial footplate and perilymphatic gusher (DFN3). Adv Otorhinolaryngol 2002;61: 161-67 Medline

48. Snik AF, Hombergen GC, Mylanus EA, et al. Air-bone gap in patients with X-linked stapes gusher syndrome. Am J Otol 1995;16:241-46 Medline

49. Makarem AO, Linthicum FH. Cavitating otosclerosis. Otol Neurotol 2008;29:730-31 CrossRef Medline

50. Makarem AO, Hoang TA, Lo WW, et al. Cavitating otosclerosis: clinical, radiologic, and histopathologic correlations. Otol Neurotol 2010;31:381-84 CrossRef Medline

51. Richard C, Linthicum FH Jr. An unexpected third window in a case of advanced cavitating otosclerosis. Otol Neurotol 2012;33:e47-48 CrossRef Medline

52. Merchant SN, Rosowski JJ, McKenna MJ. Superior semicircular canal dehiscence mimicking otosclerotic hearing loss. Adv Otorhinolaryngol 2007;65:137-45 Medline

53. Van Rompaey V, Potvin J, van den Hauwe L, et al. Third mobile window associated with suspected otosclerotic foci in two patients with an airbone gap. J Laryngol Otol 2011;125:89-92 CrossRef Medline

54. Santos F, McCall AA, Chien W, et al. Otopathology in osteogenesis imperfecta. Otol Neurotol 2012;33:1562-66 CrossRef Medline 